\title{
BIOCHEMICAL MODIFICATION OF TITANIUM SURFACES: PEPTIDES AND ECM PROTEINS
}

\author{
Marco Morra
}

Nobil Bio Ricerche, Villafranca d'Asti, Italy

\begin{abstract}
This paper reviews current approaches to the enhancement of bone regeneration at the interface with implant devices, by immobilization of biomolecules to titanium surfaces. In particular, techniques based on surface linking of peptides or extracellular matrix $(\mathrm{ECM})$ proteins are reviewed, trying to describe surface modification approaches and to present results of chemico-physical and biological evaluations, both in vitro and in vivo. Based on existing literature, surface modification by peptides or ECM proteins appears as an effective way to stimulate bone regeneration over that provided by titanium, as suggested by basic studies and in vitro results and confirmed by in vivo findings.
\end{abstract}

Key words: Titanium implants, surface modification, surface analysis, peptides, ECM proteins, collagen

\author{
Address for correspondence: \\ Marco Morra \\ Nobil Bio Ricerche \\ Str. S. Rocco 36 \\ 14018 Villafranca d'Asti \\ Italy \\ Web: www.nobilbio.it
}

Tel: +390141942446

Fax: +390141941956

E-mail: mmorra@nobilbio.it

\section{Introduction}

Titanium is the material of choice for load-bearing, bone contacting applications since the pioneering work of Branenmark. Titanium implant devices are being widely used for a variety of indications and most of the various techniques in use are evidence-based and predictable. Interfacial interactions at the bone-implant interface are recognised as the key to osseointegration and an extensive literature exists on titanium surfaces and interfaces (Davies, 1991; Davies, 2000; Brunette et al., 2001). A huge number of approaches to the surface modification of titanium, to improve further clinical results and extend the spectrum of indications, exist as well. Despite its significant success as a biomaterial, titanium and its surface are still actively investigated: for instance, in dental implantology, the need exists to address difficult clinical settings, e.g. an intended implant site compromised because of poor bone quality. The latter definition, from a clinical point of view, encompasses for instance low bone density, in the case of highly cancellous bone, or low vascularity, in the case of primarily cortical bone, or insufficient quantity of bone (in terms of the width of the alveolar ridge). In the field of artificial vertebral discs, Cunningham suggested recently that the most important and most challenging aspect is for the implanted device to encourage osseointegration at the bone-metal interface, while preserving the biomechanical properties of motion (Cunningham, 2004). In both dental implantology and orthopaedic applications the increase in life expectancy poses new challenges (and opens new markets) for surface treatment of implant devices, able locally to improve bone density or to accelerate initial healing times during integration even in old or, in general, pathologic bone.

Briefly, many open issues still exist, despite the huge literature and applications mentioned earlier. Traditionally, the approach to surface modification of titanium has been based on the control of surface topography (Brunette et al., 2001), on ceramic coatings, and, more recently, on physicochemical (Rupp et al., 2006) or inorganic approaches (Cooper et al., 2006). Currently, a significant research effort is aimed at the Biochemical Modification of Titanium Surfaces (BMTiS). Puleo and Nanci (1999) provided a clear definition of this field a few years ago: "Biochemical surface modification endeavours to utilize current understanding of the biology and biochemistry of cellular function and differentiation. Much has been learned about the mechanisms by which cells adhere to substrates, and major advances have been made in understanding the role of biomolecules in regulating differentiation and remodelling of cells and tissues, respectively. The goal of biochemical surface modification is to immobilize proteins, enzymes, 
or peptides on biomaterials for the purpose of inducing specific cell and tissue responses or, in other words, to control the tissue implant interface with molecules delivered directly to the interface.... In contrast to calcium phosphate coatings, biochemical surface modification utilizes critical organic components of bone to affect tissue response".

A few years after the previous definition, the number of studies and the interest for this field are rising constantly. In a recent forum on dental implant surfaces, Hammerle (2005) commented as follows: "Another fascinating area of development is the possibility of binding bonestimulating agents to implant surfaces. Increased understanding of the function of growth factors and extracellular matrix proteins regarding the recruitment, attachment, proliferation, and differentiation of osteoblasts has lead to extensive research in this field. .... In summary, the topographic design of implant surfaces has reached a high degree of sophistication. Additional physical modifications, such as increasing the surface energy of the implant, can probably further improve osteointegration. Major progress, however, is expected to occur when surfaces with bone-stimulating agents become available" This review tries to gather existing pieces of evidence that substantiate the fascinating scenario defined by the previous quotations. In particular, perusal of the scientific literature shows that BMTiS can roughly be itemised in the following classes, even if some overlap exists: surface modification by peptides; surface modification by ExtraCellular Matrix (ECM) proteins; surface modification by Bone Morphogenetic Proteins (BMPs) and growth factors; approaches based on pharmacologically active biomolecules. Most approaches involve the surface immobilization of the mentioned biomolecules, others especially when it comes to BMPs and growth factors, are based on controlled release or local application. Due to the width of the field, this review focuses on existing literature on BMTiS by immobilization of peptides and ECM proteins. Methods based on BMPs or growth factors, including those involving their delivery, will be discussed in a forthcoming paper.

BMTiS is eminently multidisciplinary in nature and could be approached from different viewpoints. In this paper, the author tried to follow the guidelines listed below:

- what molecules were used?

- what mechanism was targeted?

- how were molecules linked to the surface?

- how was it confirmed that molecules are indeed on the surface?

- what are biological results, either in vitro or in vivo?

- were improvements over non-biochemical treatments obtained?

The papers that are reviewed are those that present data on BMTiS by peptides or ECM proteins, not those that deal with basic studies on peptides or ECM protein function or their solution properties. For each of the two quoted groups, an initial section covers physicochemical and in vitro studies, while a second section presents in vivo results. Some papers not dealing explicitly with Ti surfaces, but involving surface immobilization and of interest to follow the general evolution of the field are reported as well. Papers are, in general, presented in chronological order. Exceptions are however made, for instance, when it is more convenient to follow straight away the evolution of the work from the same group, or to discuss together works involving the same molecule.

\section{BMTiS by linking of peptides}

The ability of cells to adhere to an extracellular material, proliferate and organise extracellular matrix molecules into a functional tissue is central to successful tissue genesis (Miyamoto et al., 1998). A heterodimeric cell membrane receptor family known as integrins is involved in cell adhesion (the first step in the sequence of cell attachment) to extracellular matrix proteins (Lebaron et al., 2000). Integrins interact with short amino acid sequences within extracellular matrix molecules. In particular, the sequence Arg-Gly-Asp (RGD) has been identified as mediating attachment of cells to several plasma and extracellular matrix proteins, including fibronectin, vitronectin, type I collagen, osteopontin and bone sialoprotein (Grzesik and Robey, 1994). It has been shown that synthetic peptides that contain the amino acids RGD, such as GRGDSP (GlyArg-Gly-Asp-Ser-Pro), can essentially mimic cell attachment activity of the parental molecule (Pierschbacher and Ruoslahti, 1984a; Pierschbacher and Ruoslahti, 1984b). Cellular recognition of simple peptides suggests their potential usefulness of conveying particular cell adhesion properties to a material surface, thus enhancing cell-material interactions. Peptide linking to materials surfaces has since then recognised as a way for enhancing cell interactions with biomaterials (Massia and Hubbell, 1990).

The practical interest of this approach, beside the obvious interest for basic studies, stems from the consideration that a simple peptide of a few hundred Daltons only mediates cell attachment similar to its considerably larger parental molecule of multiples of a hundred thousand Daltons. Peptides can be produced synthetically, allowing precise control of their chemical composition and avoiding issues related to concerns on proteins from animal sources. Relative to high-molecularweight proteins, peptides are generally more resistant to denaturing insults such as variations in $\mathrm{pH}$ and heat. The widespread view, just quoted, is probably a bit simplistic (proteins size, shape and conformation are not merely an unnecessary complication, rather they are crucial for protein function), yet it is true that clever synthetic work can provide peptides able to stimulate specific cell behaviour, as discussed in the following section.

\section{BMTiS by linking of peptides. Analytical and In vitro studies}

Dedicated studies on the effect of surface linked peptides on osteoblast behaviour start in the second half of the nineties. Among them, Dee et al. (1996) provided examples of effects on osteoblasts of RGDS (Arg-Gly-Asp-Ser) immobilized to surface-aminated glass. In an interesting paper they elaborate on the observation that RGD mediated adhesion does not account completely for osteoblast 
adhesion (Dee et al., 1998). For instance, association between cell-membrane heparan sulphate proteoglycans and heparin binding sites in ECM proteins can play a role too. For this reason, the heparan sulphate binding sequence Lys-Arg-Ser-Arg (KRSR) should be included in the rationale design of proactive bone contacting biomaterial together with RGD. Rezania and Healy (1999a), based on studies aimed at the identification of the integrin subunits responsible for the initial adhesion of human osteoblastlike cells, linked to an amino functionalized quartz surface, via a heterofucntional cross-linker, -RGD- and the heparanbinding domain -Phe-His-Arg-Arg-Ile-Lys-Ala- (FHRRIKA-) or mixtures of the two in different ratios (Rezania and Healy, 1999b). Surfaces were probed by a range of surface sensitive techniques; i.e. contact angle measurements, ellipsometry and X-ray photoelectron spectroscopy. The surface density of immobilized peptides was found in the 4-6 pmol/ $\mathrm{cm}^{2}$ range. Several aspects of the interaction of rat calvaria osteoblast-like cell with the surfaces were evaluated. In particular, following $24 \mathrm{~d}$ in culture, the areas of mineralized ECM formed on surfaces with 50 and $75 \%$-FHRRIKA- were significantly larger than those of other surfaces.

Among the first examples of peptide immobilization to titanium, Xiao et al. (1997), investigated Arg-Gly-AspCys (RGDC) binding to 3-aminopropyltriethoxylsilane (APTES) functionalized titanium surfaces. The coupling reaction involved a typical hetero-bifunctional cross-linker, N-succinimidyl-3-maleimidopropionate (SMP), reacting with the terminal amino groups on $\mathrm{Ti}$ and through covalent addition of the cysteine thiol groups of the peptide. A schematic of the process, reprinted from the quoted paper, is shown in Figure 1. The modified surfaces were evaluated by chemico-physical techniques such as X-ray photoelectron spectroscopy (XPS), radiolabelling and ellipsometry. Figure 2 shows the evolution of the carbon chemical environment during the different steps of the process, as reflected by the $\mathrm{C} 1 \mathrm{~s}$ peak obtained by XPS analysis. The growth of the $\mathrm{N}-\mathrm{C}=\mathrm{O}$ component at 289.0 $\mathrm{eV}$ indicates the introduction of maleimide and peptide bonds on the surface. From XPS data the peptide surface density was calculated to be approximately $0.03 \mathrm{nmol} / \mathrm{cm}^{2}$. This is a clear example of the important role played by surface spectroscopies (supported by and combined with other surface sensitive techniques) in monitoring the evolution of surface chemistry through the several surface modification steps often required in BMTiS. Several other very nice examples have been presented and will be reviewed later on in this section.

De Giglio et al. $(1999,2000)$ presented an approach based on the coupling of peptides to polypyrrole(PPY)coated titanium substrates. Polypyrrole can be grown electrochemically directly onto metallic substrates leading to remarkably adherent overlayers. The synthetic peptide Cys-Gly-(Arg-Gly-Asp)-Ser-Pro-Lys (CG(RGD)SPK) was grafted to the polymer substrate via the cysteine residue. The effectiveness of grafting was monitored by XPS. A higher adhesion of neonatal rat calvarial osteoblasts to RGD-modified PPy-coated Ti as compared to unmodified PPy-coated Ti and glass coverslip substrates was detected. According to the Authors, the peptide surface

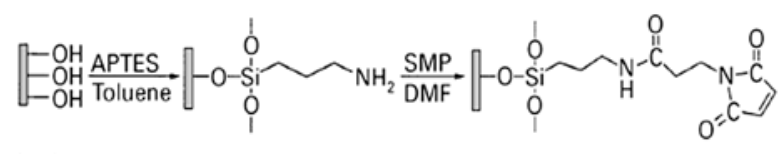

$$
\text { Surface } A
$$

Figure 1. Sequence of titanium surface modification according to the approach described by Xiao et al. (1997). Ti surfaces are amino-functionalized by 3aminopropyltriethoxylsilane (APTES).The coupling reaction involvs $\mathrm{N}$-succinimidyl-3-maleimidopropionate (SMP) reaction with the terminal amino groups on $\mathrm{Ti}$ and through covalent addition of the cysteine thiol groups of the Arg-Gly-Asp-Cys (RGDC) peptide. Reprinted from Figure 1 of Xiao SJ, Textor M, Spencer ND, Wieland M, Keller B, Sigrist H (1997) Immobilization of the cell-adhesive peptide Arg-GlyAsp-Cys (RGDC) on titanium surfaces by covalent chemical attachment. J Mater Sci Mater Med 8:867872, original copyright Chapman and Hall, with kind permission of Springer Science and Business Media.

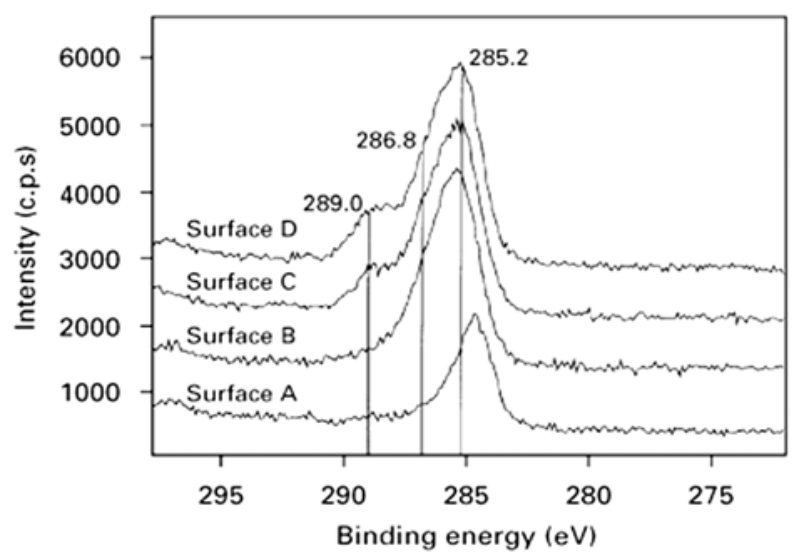

Figure 2. Evolution of the carbon chemistry on $\mathrm{Ti}$ surface modified according to the method shown in Figure 1, as detected by the shape of the $\mathrm{C} 1 \mathrm{~s}$ peak obtained by XPS analysis. The growth of the $\mathrm{N}-\mathrm{C}=\mathrm{O}$ component at $289.0 \mathrm{eV}$ indicates the introduction of maleimide and peptide bonds on the surface. Reprinted from Figure 2 of Xiao SJ, Textor M, Spencer ND, Wieland M, Keller B, Sigrist H (1997) Immobilization of the cell-adhesive peptide Arg-Gly-Asp-Cys (RGDC) on titanium surfaces by covalent chemical attachment. J Mater Sci Mater Med 8: 867-872, original copyright Chapman and Hall, with kind permission of Springer Science and Business Media.

density achieved by this approach was of the order of a few nmoles $/ \mathrm{cm}^{2}$.

Concerning the relevance of peptide surface density on cell behaviour, an interesting study was presented by Rezania and Healy (2000). RGD-modified quartz surfaces with ligand densities varying over two orders of magnitude were prepared to assess the long-term function of 
osteoblasts on peptide-derivatised surfaces, using the 15 amino acid peptide Ac-Cys-Gly-Gly-Asn-Gly-Glu-ProArg-Gly-A s p - Thr - Tyr-Arg - A la - Tyr- $\mathrm{NH}_{2}$ (CGGNGEPRGDTYRAY). After 3 weeks in culture, surfaces modified at a density above $0.62 \mathrm{pmol} / \mathrm{cm}^{2}$ significantly enhanced mineralization compared with a RGD surface density of $0.01 \mathrm{pmol} / \mathrm{cm}^{2}$, control RGE (ArgGly-Glu) surfaces, or clean surfaces adsorbed with serum proteins.

Another approach was presented by Bearinger et al. (1998). Quartz samples were surface modified by interpenetrating Polymer network (IPN) coating. The IPN was a thin adherent film (approximately $20 \mathrm{~nm}$ ) comprised of acrylamide (AAm), ethylene glycol (EG), and acrylic acid (AA) - grafted my means of photoinitiated free radical polymerisation. These networks were further modified to promote specific cell adhesion by tethering peptides. Surface characterization was performed by contact angle measurements, spectroscopic ellipsometry and X-ray photoelectron spectroscopy. Rat calvarial osteoblasts attached to Arg-Gly-Asp (RGD) modified IPNs at levels significantly greater than on clean quartz, Arg-Gly-Glu (RGE) modified, with or without serum in the media. Cell adhesion and mineralized ECM formation were dependent specifically on the peptide sequence present at the surface. The same approach was later applied to titanium surfaces (Barber et al., 2003). In this case an RGD containing 15 amino acid sequence from rat bone sialoproteins was linked to the IPN coating on Ti. The paper presents an accurate characterization of the treated surface by XPS. Significant improvements in bone mineralization by primary rat calvarial osteoblast were reported.

Kantlehner et al. (2000) investigated the behaviour of cyclic c(-RGDfK-) (Arg-Gly-Asp-Dphe-Lys). This peptide is $\alpha(\mathrm{v}) \beta(3)$ - and $\alpha(\mathrm{v}) \beta(5)$-integrin-selective and, using the lysine side chain of c(-RGDfK-), it was bound to a number of linker molecules containing an acrylamide end group. The acrylamide group can be used to bind the peptide covalently to acrylate polymer surfaces. In studies involving the surface modification of polymethylmethacrylate (PMMA), the coated surfaces effectively bind to murine osteoblasts as well as human osteoblasts in vitro when a minimum distance of $3.5 \mathrm{~nm}$ between surface and the constrained RGD sequence is provided. Some in vivo data were also provided, showing that peptide-coated PMMA pellets implanted into the patella groove of rabbits were integrated into the regenerating bone tissue faster and more strongly than uncoated PMMA pellets.

A nice study on the importance of the interfacial microenvironment of immobilized RGD has been presented by Houseman and Mrksich (2001). Using the SAMs on gold approach, systems composed by mixtures of RGD and oligo(ethylene glycol) groups, that resist the nonspecific adsorption of proteins were prepared. The surface density of peptides ranged from 17 to $0.7 \mathrm{pmol} /$ $\mathrm{cm}^{2}$. The microenvironment of the peptide ligands was controlled by using thiols that present either tri-, tetra-, penta-, or hexa(ethylene glycol) units, changing in this way the average distance separating the glycol groups and the peptide ligand, while the structure and properties of the background remain unchanged. It was found that cell attachment to monolayers, presenting a fixed density of peptide, decreased as the length of the oligo(ethylene glycol) group increased. At lower densities of immobilized peptide, decrease was more pronounced. Attachment and spreading did not depend on the density of peptide on monolayers presenting tri(ethylene glycol) groups, but showed a high sensitivity to the density of ligand on monolayers presenting longer glycol oligomers. These results are a clear indication that the microenvironment of the peptide ligand influences the affinity of the integrinpeptide.

Dettin et al. (2002) investigated peptides carrying RGD motifs and of sequences mapped on human vitronectin. Osteoblast adhesion experiments on polystyrene plates coated with the peptides were presented. Peptides were simply passively adsorbed to the PS surface, no surface characterization data were presented. An interesting novel peptide, carrying the X-B-B-B-X-B-B-X motif (where $\mathrm{B}$ is a basic amino acid and $\mathrm{X}$ is a nonbasic residue), was shown to promote proteoglycan-mediated osteoblast adhesion very effectively.

Cavalcant-Adam et al.(2002), confirmed the improvement of osteoblast activity on flexible silicone surfaces where RGD peptides were covalently linked to surface amino groups introduced by silane chemistry. Huang et al. (2003) investigated gold-coated titanium surfaces. Using SAMs techniques, two types of peptides, RGDC (Arg-Gly-Asp-Cys) and RDGC (Arg-Asp-GlyCys), were immobilized. Surface characterization involved $\mathrm{X}$-ray photoelectron spectroscopy and Fourier transform infrared spectroscopy. Cell culture tests of primary calvarial osteoblasts were performed. Four and 8 hours after culture, cell attachment was enhanced on RGDC surfaces. Increased cell spreading and significantly greater cell proliferation were also observed in cells grown on the RGDC-coated surfaces. Interestingly, osteoblasts on RGDC surfaces showed osteocalcin (OC) mRNA expression at day 15 , that is significantly earlier as compared with controls: osteoblasts on Ti and RDGCcoated surfaces began to show OC mRNA expression just at day 21, providing evidence of the enhanced functions of osteoblasts cultured on the RGDC-modified surfaces.

Zreiqat et al. (2003) presented a very interesting paper that not only discusses the effect of surface-tethered RGD peptides on bone cells adhesion and differentiation, but also on bone remodelling. Briefly, a thirteen amino-acid RGD peptide Gly-Arg-Gly-Asp-Ser-Pro-Tyr-Gly-GlyGly-Gly-Gly-Cys (GRGDSPYGGGGGC) was linked to Ti-6Al-4V (Ti grade 5) surfaces aminated by silane chemistry, through the thiol on the cysteine residue and a maleimide coupler. An analogous peptide bearing the nonadhesive RGE (Arg-Gly-Glu) sequence was coupled as well as a control. Surface characterization was nicely performed by XPS analysis and the surface density of peptides was estimated by radio-labelling, resulting in the range of $40 \mathrm{pmol} / \mathrm{cm}^{2}$. Human bone-derived cells, obtained from bone removed at hip replacement, were cultured on peptide-coated and control surface. A number of biological 
parameters were measured, confirming - in agreement with previously quoted papers, that RGD coated titanium surfaces appear to promote differentiation of osteoblasts. In particular, the expression of bone matrix mRNA was enhanced on RGD surfaces as compared to other samples: increased expression of mRNAs for osteocalcin (at 7 days), pro-collagen I (at 7 days), alkaline phosphatase (at 14 days, Figure 3) on the RGD bound Ti-6Al-4V, compared with the native Ti-6Al-4V was found. Therefore, RGD appears to promote differentiation of osteoblasts more than the other substrates by enhancing the expression of bone matrix mRNAs. By the evaluations of molecules involved in the control of osteoclastogenesis, it was found that all tested surfaces promote osteoclast formation and bone turnover, that is this effect seems more related to general surface properties and not to the specific cellular recognition and activity of RGD sequence.

Another interesting multidisciplinary study has been provided by Porte-Durrieu et al.(2004). Two RGD containing peptides displaying a different conformation were linked to Ti-6Al-4V alloy surfaces: linear RGD and cyclo-(Asp-Dphe-Lys(mercaptopropionyl)-Arg-Gly) (cyclo-DfKRG). The coupling reaction involves silanization with APTES, cross-linking with SMP and finally immobilization of peptides thanks to thiol bonding, and in-depth discussion is presented on the role and importance of surface preparation. The surface chemistry, after the different steps, was evaluated by XPS. The density of peptides grafted onto the surface was found to be around $20 \mathrm{pmol} / \mathrm{mm}^{2}$, by radioactivity measurement. Evaluation of the adhesion between 1 and $24 \mathrm{~h}$ of osteoprogenitor cells isolated from human bone marrow shows significant improvement over the untreated surface, and better results for the cyclic peptide over the linear one for $24 \mathrm{~h}$ data. A recent paper by the same group (Pallu et al., 2005) extends the previous work, investigating the differentiation of human osteoprogenitor cells: in this case, cyclo-DfKRG is either covalently linked as described before or simply adsorbed to Ti6Al4V surfaces. In the latter case, both a thiol and a phosphonate anchor are tested. Significant differences were found comparing "covalent linking" Vs. "adsorption procedure".

While previous approaches to surface modification are mostly based on the coupling of peptides to aminofunctionalized surfaces, an alternative way was suggested and investigated by Xiao et al. (2001), Tosatti et al.(2003, 2004) and Hansson et al. (2005). Briefly, poly-(L-lysine) (PLL), like other polycations, irreversibly adsorbs to negatively charged surfaces. A graft copolymer was synthesized, containing poly-(L-lysine) (PLL) as the substrate-binding and poly(ethylene glycol) (PEG) as protein adsorption-resistant pendant side chains (PLL-gPEG) (Van der Vondele et al., 2003). A fraction of the grafted PEG was functionalized by covalent conjugation to the peptide motif RGD to induce cell binding. This graft copolymer adsorbs spontaneously from dilute aqueous solution onto negatively charged surfaces, yielding waterstable coatings. Several properties of coatings obtained by this approach were tested.

An interesting paper by this group highlights many of

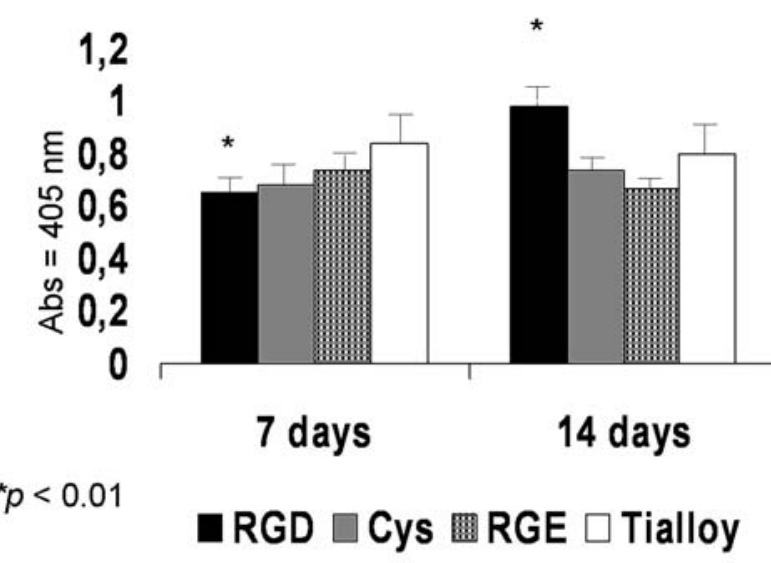

Figure 3. Expression of alkaline phosphatase mRNA by human bone-derived cells cultured on peptidemodified titanium alloy surfaces for 7 and 14 days. In situ hybridization and immunohistochemistry-based ELISA assays using microtiter plate method. Mean of six wells \pm standard deviation. Graph of a representative experiment of four replicates. Data show increased expression of mRNAs for alkaline phosphatase at 14 days on the RGD bound Ti-6Al-4V, compared with the native Ti-6Al-4V and with the other controls. Reprinted from Zreiqat $\mathrm{H}$ et al., 2003, with permission.

the basic questions of this field (Tosatti et al., 2004). Briefly, MG63 immature osteoblast-like cells were cultured on smooth Ti surfaces (both smooth and rough) that were modified with adsorbed monomolecular layers of PLL-gPEG. Coatings were functionalized with varying amounts of a RGD peptide Gly-Cys-Arg-Gly-Tyr-Gly-Arg-GlyAsp-Ser-Pro-Gly (GCRGYGRGDSPG), coded PLL-gPEG/PEG-RGD or a nonbinding RDG control sequence Gly-Cys-Arg-Gly-Tyr-Gly-Arg-Asp-Gly-Ser-Pro-Gly (GCRGYGRDGSPG) coded PLL-g-PEG/PEG-RDG. The peptide surface concentration was varied between 0 and $6.4 \mathrm{pmol} / \mathrm{cm}^{2}$. The striking evidence from this paper is that the scarcely cell-adhesive PLL-g-PEG induces more cell differentiation than the RGD bearing polymer. As suggested in the paper, these results exemplify the inverse relationship between proliferation and differentiation often remarked in vitro. The shift observed from low cell number but high phenotype expression on PLL-g-PEG to high cell number but reduced phenotype expression on PLL-g-PEGRGD suggests that RGD binding may reduce differentiation of osteoblasts to an extent conducive to proliferation rather than stimulating differentiation. This fundamental topic of BMTiS will be discussed again several times later on, while comparing peptides and ECM proteins modifications.

The same groups has recently presented a study comparing cell adhesion and morphology to control and RGD functionalized-PLL-g-PEG coated machined and roughened titanium implants (Schuler et al., 2006). Osteoblast attachment and footprint areas increased with increasing density of the RGD-containing peptide and this effect was not affected by surface topography (i.e smooth Vs. rough). 
An interesting paper by Senyah et al. (2005) reminds that caution is always required before attributing a given effect on cell behaviour to specific peptide bioactivity. More general surface properties, such as hydrophobicity/ philicity, are always at work over and above specific effects. Changing, for instance, the peptide sequence may result (and, in general, does result) in the modification of unspecific surface properties at large, and this in turn will affect cell adhesion to a given surface. In the quoted paper (Senyah et al., 2005) RGD sequences were linked to borosilicate glass and titanium surfaces using silanisation chemistry. Successful peptide immobilisation was proven by fluorimetric measurements and confocal image analysis. In vitro cell proliferation assays were employed to compare the adhesion potentials of RGD containing peptides to the three peptides designed by Senyah and coworkers. Results show that the RGD sequence is not necessarily required to enhance the adhesion of cells to non-biological surfaces and that the number of adhering cells can be increased by changes in the peptide hydrophobicity.

Reyes and Garcia $(2003,2004)$ presented an interesting approach aimed at engineering of bioadhesive surfaces that specifically target the $\alpha_{2} \beta_{1}$ integrin. To achieve this goal they designed a stable, triple-helical, collagen-mimetic peptide that contains the GFOGER (Gly-Phe-HydroxyproGly-Glu-Arg) hexapeptide sequence from residue 502-507 of the alpha(I) chain of type I collagen. Three different coupling schemes were tested successfully to link the active peptide to polystyrene surfaces. Studies on focal adhesion of MCT3T3-E1 cells show that the surface-immobilized GFOGER not only promotes adhesion comparable to type I collagen, but it also may mimic post-adhesion signalling similar to collagen coated surfaces. A couple of recent reviews by the same Authors provide broad overviews on the subject (Garcia and Reyes, 2005; Garcia, 2005)

Recent activity has focused on new approaches to peptide immobilization. Auernheimer et al. (2005) and Auernheimer and Kessler (2006) have discussed coating titanium implants with a tailor-made cyclic-RGD peptide, presenting approaches to coat titanium by peptides bearing phosphonic acid groups.

Groll et al. (2005) presented an interesting approach, based on immobilization to Ti surfaces of reactive starshaped poly(ethylene glycol) prepolymers (Star PEG). The surface deposited films were modified with linear RGD peptides in different concentrations. Human mesenchymal stem cells (hMSC) failed to adhere to unmodified Star PEG layers, while adhesion and growth occurred on peptide modified substrates. Cells show the expression of osteogenic marker genes after 14 days, a time comparable to cultivation on cell culture plastic, leading to the conservative statement that the Star PEG/RGD film did not influence negatively the differentiation process.

Other interesting reflections on the role of immobilized peptides are contained in a recent paper by Ku et al. (2005), that investigated the effect of recombinant fragment of fibronectin and vitronectin that contains the binding site for integrins. Fragments were passively adsorbed to Ti discs. MC3T3-E1 cells seeded upon the fibronectin fragment-coated titanium showed a marked increase in cell adhesion, proliferation, and differentiation over the other test sample. In this paper, the inverse relationship between proliferation and differentiation detected in previously quoted work by Tosatti et al. (2004) was not detected.

\section{BMTiS by linking of peptides. In vivo studies}

The first in vivo study showing evidence of increased bone formation by RGD coated implants was presented by Ferris et al. (1999). A study was designed to evaluate the quality and quantity of the new bone formed in response to titanium rods surface-coated with the peptide sequence Arg-Gly-Asp-Cys (RGDC) in rat femora. The peptide was immobilized to the surface using the chemistry commonly adopted for SAMs: smooth titanium samples were gold coated and RGDC immobilized using gold-thiol chemistry in water-alcohol solutions. Samples were sterilized in alcohol. Histomorphometric analysis showed a significantly thicker shell of new bone formed around RGD-modified versus plain implants at 2 and 4 weeks. Mechanical pull-out testing conducted at 4 weeks revealed that the average interfacial shear strength of peptide modified rods was greater than control rods, although this difference was not statistically significant. As remarked in the paper (possibly following specific referees comments), the study did not include a non-specific peptide control, so that the question remains open whether the observed improvement was due to non-peptide-related non-specific interactions. Also, the paper does not show any data on surface characterization of the test samples.

Schliephake et al. (2002) failed to detect benefits due to organic coating of titanium implants on periimplant bone formation and bone/implant contact. In particular, implants with square cross-sections were inserted press fit into mandibles of 10 beagle dogs. Peptides were linked to a collagen coating. Implants (Ti6Al4V) had a polished surface, a collagen coating, and collagen coating with covalently bound RGD peptides. Bone formation was evaluated by morphometric measurement of the newly formed bone around the implant and the percentage of implant bone contact. Samples were examined at 1 and three months. Differences between the surface types were not significant, providing only weak evidence that coating of titanium implants with RGD peptides in the form used may increase periimplant bone formation in the alveolar process. This approach will be discussed again while describing more recent work by the same group.

A submitted, but readily available paper by Germanier et al. (2004, the web address is indicated in the reference list), presents in vivo results on the approach by Tosatti and coworkers described in the previous section. Starting from Sandblasted Large grit Acid etched (SLA) titanium implant surfaces the following samples were prepared (notation is that reported in the previous section): SLA+ (PLL-g-PEG); SLA + (PLL-g-PEG/PEG-RDG), that is a PEG coating biofunctionalized with the inactive peptide (Arg-Asp-Gly); SLA + (PLL-g-PEG/PEG-RGD], that is a PEG coating biofunctionalized with the active (Arg-GlyAsp) sequence. Implants were placed in the maxilla of miniature pigs; histology was performed at 2 and 4 weeks. Evaluation at 2 weeks shows that only the active (PLL-g- 
PEG/PEG-RGD] coating gives statistically significant improvement of bone to implant contact (BIC) over that afforded by SLA alone. Statistical comparison between the different coatings is not provided. At 4 weeks, both "non specific" coatings, that is (PLL-g-PEG) and the inactive (PLL-g-PEG/PEG-RDG) yield statistically significant improvement over the control SLA and the bioactive SLA + (PLL-g-PEG/PEG-RGD] surface. No clear explanation for this result can be suggested. An interesting observation from the data, reported in Table 2 of the paper, is that the RGD surface is the only one that does not show any BIC growth from 2 to 4 weeks. The actual meaning and implications of these data are not known and require more in depth investigations.

Kroese-Deutamn et al. (2005), evaluated new bone formation in a porous titanium (Ti) fibre mesh implant, coated with cyclic RGD peptide containing a phosphonate anchor. The titanium meshes were soaked in the coating solution and the peptide was allowed to immobilize overnight. Samples were sterilized by gamma sterilization (25 kGy). The RGD-Ti implants were inserted into the cranium of a rabbit and were compared with porous titanium fibre mesh disks without RGD sequence and with an open control defect. Histologic and histomorphometric examinations were performed 2, 4 and 8 weeks postoperatively. A significant increase in bone formation, or bone ingrowth, was detected in the RGD-Ti group compared with the Ti group after 4 and 8 weeks.

Elmengaard et al.(2005a,b), recently presented two interesting papers on the in vivo effects of RGD coated titanium in press-fit and bone-defects models. In the first study (2005a), sixteen unloaded cylindrical plasma sprayed Ti6Al4V implants coated with cyclic RGD peptide were inserted as press-fit in the proximal tibia of 8 mongrel dogs for 4 weeks. Uncoated control implants were inserted in the contralateral tibia. Bone ongrowth increased significantly and fibrous tissue ongrowth was significantly reduced for RGD-coated implants. Bone volume was significantly increased in a $0-100$ micron zone around the implant and increases in median ultimate shear strength and energy to failure were also observed. In the second study (2005b), the effects of cyclic RGD-coated implants on tissue integration and implant fixation in two cancellous bone-gap models in canine were evaluated. Plasmasprayed Ti-6Al-4V implants were investigated at 4 weeks, the fixation was evaluated by push-out test and histomorphometry. Mechanical implant fixation was improved for RGD-coated implants. Unloaded RGDcoated implants showed a significant increase in bone whereas both loaded and unloaded implants showed a significant reduction in fibrous tissue anchorage.

Both studies were performed using a RGDfK (ArgGly-Asp-Dphe-Lys) peptide with a thiol anchor. Coating was performed in a $100 \mu \mathrm{M}$ solution in phosphate buffer, for $24 \mathrm{~h}$, followed by washing. The papers do not report surface characterization data or info on the surface peptide density.

The last two works reported in this section are ideal links with the following one on surface modification by ECM proteins. Schliephake et al. (2005), a work of this group has already been quoted (Schliephake et al., 2002), evaluated periimplant bone formation around titanium screws implanted in dog. Briefly, ten adult female foxhounds received experimental titanium screw implants in the mandible, 3 months after removal of all premolar teeth. Four types of implants were evaluated in each animal: implants with machined titanium surface, implants coated with collagen I, implants with collagen I and cyclic RGD peptide coating (Arg-Gly-Asp) with low and high RGD concentrations. Here low and high RGD concentration is related to the peptide concentration in the coating solution, $100 \mu \mathrm{mol} / \mathrm{mL}$ and $1000 \mu \mathrm{mol} / \mathrm{mL}$ respectively. Collagen was linked to the titanium surface by low voltage anodization $(5 \mathrm{~V})$, followed by dip-coating in collagen and cross linking by carbodiimide chemistry up to a surface density of $44 \mu \mathrm{g} / \mathrm{cm}^{2}$. Peptides, bearing pendant acrylate groups, were UV grafted to the collagen coated implants. No surface chemistry data are reported in the paper, concerning collagen and collagen/peptides modified implants. Periimplant bone regeneration was assessed histomorphometrically after 1 and 3 months in five dogs each by measuring bone implant contact (BIC) and the volume density of the newly formed periimplant bone (BVD). After 1 month, BIC was enhanced significantly in the group of implants coated with the higher concentration of RGD peptides as compared to Ti surface; however, no significant difference was detected between groups with organic coating (collagen and RGD low and high). Volume density of the newly formed periimplant bone was significantly higher in all implants with organic coating. Again, no significant difference was found between collagen coating and RGD coatings. After 3 months, all implants with organic coating gave better results than uncoated implants, without showing differences between the three different groups. Briefly, type I collagen alone performed without statistically significant difference as compared to RGD coatings. After all, the reason why RGDs are of interest is that they are contained in collagen. This topic will be discussed later on.

The last paper reviewed in this section contains again a comparison between RGD and collagen. In a very interesting paper, Bernhardt et al. (2005) evaluated titanium implants coated with collagen type I, type III, or RGD peptide, and placed in the femur of goats together with an uncoated reference. Collagen coatings were performed after allowing overnight fibrillar assembly. Cyclo(-RGDfK)(-tetraphosphonyl-lysil-lysil-diamidoheptaethyleneglycol), where the four phosphonate groups act as an anchor, was surface linked by surface adsorption followed by anodization at $4 \mathrm{~V}$. All samples were sterilized by gamma rays. Bone contact and volume were determined after 5 and 12 weeks implantation, using both histomorphometry and synchrotron radiation micro computed tomography (SR $\mu \mathrm{CT}$ ). Both methods revealed similar tendencies in bone formation for the differently bio-functionalized implants: after 5 and 12 weeks, all three coatings showed a significant increase in bone volume over the uncoated reference, with the highest results for the collagen coatings, while the RGD coating showed only a slight improvement compared with the reference material. 
Interestingly, collagen type III, appeared to be the more effective coating in areas of less dense spongious bone. While this point will be discussed in more depth in the following section, it is of interest to close the present section by quoting the comments of Bernhardt and co-workers on the superiority of collagen over RGDs: "as RGD is not involved in further signalling events like the larger matrix molecules due to their much higher number of potential interaction sites, cell adhesion may not be the only element involved in cell response to implants".

\section{BMTiS by ECM proteins}

The last sentence of the previous section introduces BMTiS by ECM proteins. If, from one side, it is submitted that the practical interest of peptide-based approaches is that a simple peptide of a few hundred Daltons only replicates the behaviour of its considerably larger parental molecule of multiples of a hundred thousand Daltons, the question is how far this tenet holds. An interesting study by Jikko et al. (1999) addresses some crucial point of collagen and its peptides' role in osteoblast differentiation. Actually, as discussed in the following, many studies involving ECM proteins are based on collagen. Collagen, and the cellbinding domains it contains, play an important role in osteoblast cells behaviour (Lebaron et al., 2000), promoting not only cell adhesion but also osteoblastic differentiation of bone marrow cells and controlling a number of aspects of their progression along the osteogenic pathway (Jikko et al., 1999; Mizuno et al., 2000; Salasznyk et al., 2004). Based on existing literature, it is then possible to speculate that collagen coated surfaces can either or both recruit more osteogenic cells precursors; and provide a more favourable environment for osteogenic cells' differentiation following instructions from cell-matrix interactions and from diffusible molecules. These principles are at the basis of BMTiS by collagen and ECM proteins in general, and will be reviewed in the following sections.

\section{BMTiS by ECM proteins. Analytical and In vitro studies}

Literature analysis shows that early papers on surface modification of Ti by proteins were mostly concerned with improving adhesion of the soft tissue to implants, this way promoting a stable seal that could avoid bacterial invasion of the bone-contacting portion. In this vein, Lowenberg et al. (1988) coated porous Ti6AI4V discs with collagen and with collagen incorporating platelet-derived growth factor (PDGF); coated discs exhibited significantly higher attachment and orientation indices compared with controls and the orientation index was further enhanced by addition of PDGF to the collagen. It was concluded that attachment and orientation of cells on Ti can be modified by the application of biological molecules, suggesting a useful application in clinical implantology.

Dean et al. (1995) reported that fibronectin coating of Ti surfaces resulted in a two to three times enhancement of gingival fibroblast binding, with a lesser effect on epithelial cells. Laminin coating resulted in three to four times enhancement of gingival epithelial cell binding on all implant surfaces tested, with a lesser effect on fibroblasts. Thus, the two cell types exhibited distinct preferences for the different molecules tested, suggesting that cell-selective Ti surfaces are feasible, in principle. Laminin-5 coatings were investigated further by Tamura et al. (1997) and El-Ghannam et al. (1998). The first study is focused on the formation of a biological seal around the transmucosal portion of dental implants. Laminin isoform, laminin-5, a component of basement membranes, plays a crucial role in the assembly and maintenance of hemidesmosomes, that connect the gingival epithelium to dental implants. In vitro data reported in the paper show that laminin-5 as a biological coating of titanium-alloy promotes cell attachment of a gingival epithelial cell line, IHGK. IHGK cells assembled hemidesmosomes within $24 \mathrm{~h}$ of attachment to laminin-5-coated titanium alloy but not to the titanium alloy alone. In the second paper (ElGhannam et al., 1998), that contains nice surface characterization by XPS, ToF SIMS and AFM, DNA analysis showed that laminin-5 enhanced attachment of normal human epidermal keratinocytes (NHEK) to Ti-6Al$4 \mathrm{~V}$ significantly more than did laminin-1 or uncoated controls. The results were also affected by the previous surface treatment (unpassivated Vs. passivated) of Ti.

Papers presented so far were based on the passive adsorption of proteins. Methods based on covalent attachment have been presented as well. Endo (1995a,b), described the covalent linking of human plasma fibronectin (pFN) onto gamma-aminopropyltriethoxysilane (gammaAPS) functionalized NiTi substrate with glutaraldehyde through Schiff's base formation. XPS analysis was used to follow the modification of surface chemistry through the different steps, and the amount of immobilized pFN was determined by a fluorometric method. The pFN was immobilized at a surface density of $1.1 \mathrm{micrograms} / \mathrm{cm}^{2}$, and significantly promoted fibroblast spreading. Nanci et al. (1998) also used Aminosilane chemistry, while Mikulec and Puleo (1996) and Puleo et al. (2002) presented two interesting papers on the use of p-nitrophenylchloroformate chemistry to couple biomolecules to native hydroxyl groups and on amino functionalization by plasma deposition. Matsumura and co-workers presented an approach to the surface immobilization of collagen that was used also for the modification of Ti implants (Matsumara et al., 2000; Peng et al., 2001; Matsumara et al., 2002). Briefly, collagen was linked to poly(ethyleneco-vinyl alcohol) (EVA) coatings on Ti implants. An interesting paper describes adhesion and proliferation of periodontal ligament cells on this "ibrid" material, suggesting the possibility of PDL regeneration on dental implants.

The just quoted works introduce published studies on BMTiS by collagen that will take the lion share in the rest of this paper. A number of studies have demonstrated the pivotal role of collagen in modulating cell growth and differentiation; some of them have been quoted in the beginning of this section. In bone the extracellular matrix is composed of approximately $85 \%$ type I collagen and cellular interaction with matrix components has been shown to be important in the regulation of the osteoblast 
phenotype. Thus, collagen is of obvious interest in BMTiS. Geissler et al. (2000) investigated the adhesion of rat calvarial osteoblasts to uncoated and collagen type I-coated titanium over a period of $24 \mathrm{~h}$. Collagen was adsorbed passively, with and without fibrillogenesis, on TiAlV disks. Surfaces were characterized by SEM, ELISA and staining tests. Data show that collagen type I-coating accelerates initial adhesion of osteoblasts in the presence of foetal calf serum, however one hour after plating, no differences in the percentage of adherent cells between the surfaces investigated were found. Tests involving solubilized petpides suggest that osteoblasts adhere to collagen type I-coated materials by means of integrin beta1 but not by interacting with RGD peptides, whereas adhesion to uncoated titanium alloy is mediated by RGD sequences but not by means of integrin $\beta 1$.

De Giglio et al. (2001), whose work has already been quoted in the peptide section, presented an interesting approach on collagen immobilization based on polypyrrole films, directly grown on implant materials and modified by the inclusion of collagen during the polymer electrodeposition step. Surface characterization by XPS and SEM shows the effectiveness of film modifications.

Nagai et al. (2002) investigated the influence of the collagen coating, on titanium, on the initial attachment of human gingival fibroblasts. Scanning electron microscopy (SEM) was used to investigate the morphological changes of cultured human gingival fibroblasts on four different surfaces, i.e. non-coated mirror-polished titanium, collagen-coated titanium, non-coated tissue-culture polystyrene and collagen-coated polystyrene. Collagen coating of titanium effectively promoted initial cell attachment, improving the activity of human gingival fibroblasts.

Roehlecke et al. (2001) investigated the behaviour of primary osteoblasts grown on both fibrillar collagen-coated and tropocollagen-coated Ti6A14V. A number of parameters were evaluated, including cell attachment, spreading, cytoskeletal organization, focal contact formation, proliferation and expression of a differentiated phenotype. In comparison to uncoated titanium alloy, collagen-coated alloy enhanced spreading and resulted in a more rapid formation of focal adhesions and their associated stress fibres. Osteoblasts had a higher proliferative capacity on collagen coated samples and the intracellular expression of osteopontin was upregulated compared to uncoated titanium alloy. Contrary to these results, Becker et al. (2002) evaluated proliferation, differentiation, and mineralization of osteoblasts on type I collagen-coated Ti6Al4V. Precoating of the samples with type I collagen did not affect extensively, proliferation, the activity of alkaline phosphatase, collagen synthesis, calcium accumulation or the mRNA levels for collagen I alpha1, osteopontin, osteocalcin, MMP-2 and TIMP-2. The results obtained in this work suggest that collagen-coating alone is not sufficient to accelerate differentiation of rat calvarial osteoblasts on Ti6Al4V. Adsorption of collagen was performed at $25 \mathrm{C}$ for $15 \mathrm{~min}$ in phosphate buffer at pH 7, yielding a surface density of 3-6 $\mu \mathrm{g} / \mathrm{cm}^{2}$, no throughout surface characterization data are presented in the paper.
A similar result, that is the lack of significant effects due to different coatings, was presented by Van den Dolder et al. (2003). The objective of this study was to evaluate the effects of fibronectin and collagen I coatings on titanium fibre mesh on the proliferation and osteogenic differentiation of rat bone marrow cells. Three main treatment groups were investigated, in addition to uncoated titanium fibre meshes: Ti meshes were coated with fibronectin, with collagen I, and first with collagen I and then subsequently with fibronectin. Rat bone marrow cells were cultured for $1,4,8$, and 16 days on coated titanium fibre meshes and uncoated control. There were no significant effects of the coatings on cellular proliferation as indicated by the DNA quantification analysis. When antibodies against fibronectin and collagen I integrins were used, a significant reduction in cell proliferation was observed for the uncoated titanium meshes coated with collagen and meshes coated with both collagen and fibronectin. The different coatings also did not affect the alkaline phosphatase activity of the cells seeded on the coated meshes. Altogether, these results show that a fibronectin or collagen I coating does not stimulate the differentiation of rat bone marrow cells seeded in a titanium fibre mesh. Full evaluation and comparison with different results obtained by other groups are hampered by the lack of information on the true surface chemistry: as reported in the experimental section of the paper: "The meshes were used uncoated as received or coated with either fibronectin $(50 \mathrm{mg} / \mathrm{mL})$ or collagen I $(100 \mathrm{mg} / \mathrm{mL})$ or both collagen I and fibronectin. For coating, the meshes were added in a fibronectin or collagen I solution for $1 \mathrm{~h}$. During this time period, fibronectin and collagen I proteins have been adsorbed to the meshes".

Bierbaum et al. (2003a,b) have investigated coatings obtained by adsorption of collagen I, collagen III and fibronectin. The paper focuses on the effect of fibrillogenesis and fibril morphology on adsorption. Increasing the collagen type III amount, results in a decrease of fibril diameter, while no significant changes in adsorption occur. The surface density of collagen was calculated between 40 and $60 \mu \mathrm{g} / \mathrm{cm}^{2}$. Interestingly, the amount of fibronectin bound to the heterotypic fibrils depended on fibrillogenesis parameters such as ionic strength or concentration of phosphate, and varies with the percentage of integrated type III collagen. The second paper of the series addresses responses of primary osteoblastic cells from rat calvariae. Differences in alkaline phosphatase activity (ALP) and collagen synthesis were observed between differently composed collagen coatings. Also, cell shape and morphology was affected by the collagen layer thickness and nature.

Kim et al. (2005) recently investigated the stability of collagen I coating (obtained by adsorption), the role of fibrillogenesis and of crosslinking on osteoblast response (using the MG63 cell line). The degree of assembly was varied with the incubation time and the differently assembled collagen was coated on the Ti. Some samples were crosslinked by carbodiimide. It was found that both fibrillar assembly and crosslinking improve the stability of the collagen. Cellular responses were improved significantly when the collagen was assembled to fibrils 
and the assembly degree was increased. The paper stresses that some of the conflicting result reported above involving in vitro tests of adsorbed collagen could be accounted for by the different effects engendered by the different degree of assembly of collagen.

Muller and coworkers (Muller et al., 2006) have recently presented a comprehensive review on the effect of surface pre-treatment of titanium on the immobilization of fibrillar collagen. The paper describes the effect of the density of interfacial bonds and of cross-linking on the stability of surface collagen layers and on osteoblast-like cell response.

An interesting paper by Pham et al. (2003), which discussed the ultimate protein-based coating that is a native extracellular matrix coating on Ti surfaces, closes this section. Briefly, osteoblast-like SAOS-2 cells were allowed to synthesize and assemble their extracellular matrix (ECM) on titanium surfaces. After that, cells were removed selectively by exposition of the samples to $15 \mathrm{mM} \mathrm{NH} 4 \mathrm{OH}$ solution for $6 \mathrm{~min}$. The attachment, spreading and morphology of SAOS-2 cells to Ti coated with a native ECM (ECM-Ti) was compared with those to Ti and peptide sequence RGDS- or fibronectin-immobilized Ti. Results show an increase of cell density at $4 \mathrm{~h}$ in the order $\mathrm{Ti}<$ RGDS-Ti $<$ fibronectin Ti $<$ ECM-Ti, even if statistical analysis of data is not reported.

\section{BMTiS by ECM proteins. In vivo studies}

Reports on in vivo behaviour of collagen coated Ti implants have been published since a conference abstract of 2002 (Rammelt et al., 2002; Another very interesting abstract by the same group has been presented recently, Rammelt et al., 2005). The first full paper providing in vivo evidence of enhanced osteointegration by surface modifcation of Ti implants by collagen was published in 2003 (Morra et al., 2003). Type I collagen was covalently linked to a surface grafted polyacrylic acid layer. The paper reports detailed surface characterization by XPS, AFM in dry and aqueous environment and a study of the environment-dependent aqueous interface of coated Ti by AFM force distance curves. In vivo studies in rabbit femur at 4 weeks, involving EtO sterilized samples, show a significant increase of bone growth and bone-to-implant contact of collagen coated Ti as compared to control Ti implants. The histomorphometric results were later supported by more findings from the same model, showing significant improvement of mechanical parameters such as peri-implant bone microhardness (Morra et al., 2005a), and push-out force (Morra et al., 2005b). While the just quoted data were obtained on "machined" Ti surfaces, a recent paper from the same group shows the benefit of the collagen coating even on more topographically sophisticated titanium surfaces (Morra et al., 2006). The combined effect of topography and biochemical cues is indeed an interesting path of implant devices evolution. The collagen coating was applied to titanium implants surface-treated by galvanostatic anodization and characterized by nanoporous surface topography (Figure 4). Experiments in the trabecular (cancellous) bone tissue of the epiphysis of the distal femora, in a 4 weeks rabbit model, show improvements of both bone to implant contact and bone

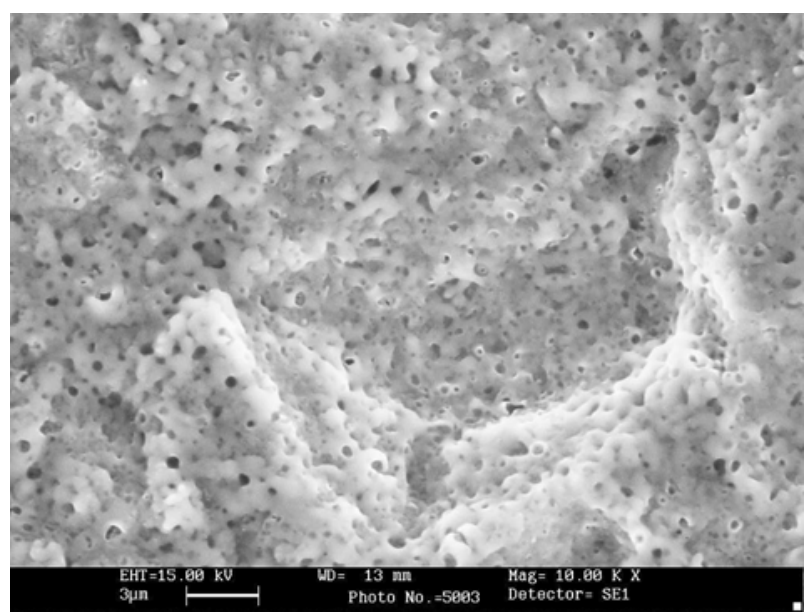

Figure 4. SEM image showing the surface topography of nanoporous Ti surface bearing a covalently linked collagen coating. The implant surface provides the superposition of topographical and biochemical cues. The calculated average pore diameter is about $350 \mathrm{~nm}$ (from Morra et al., 2006).
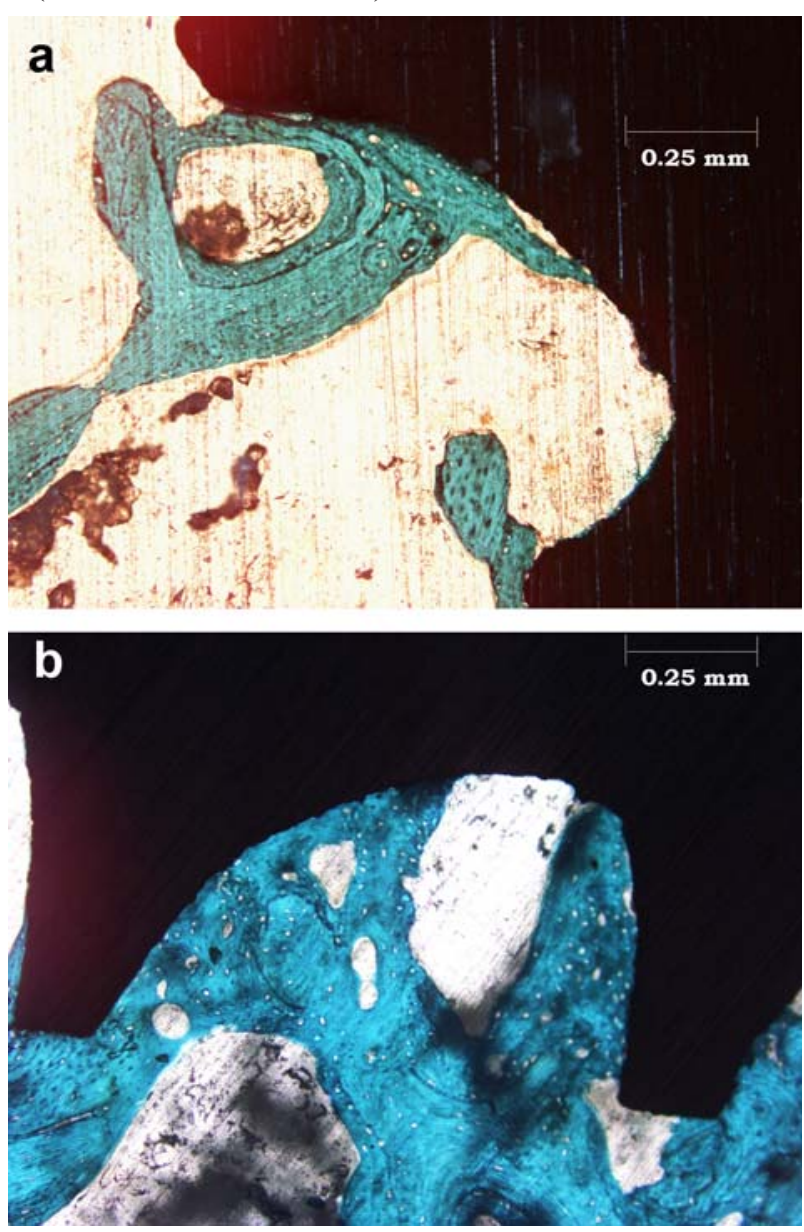

Fig. 5 Examples of histological sections obtained from 4 week implants in rabbit femur trabecular bone: a: Ti; b: collagen coated Ti. (Fast green and acid fucsin, magnification 10x, from Morra et al., 2006).

ingrowth, even if the latter is slightly not significant ( $p=$ 0.056) when compared to the control. Figure 5 shows histological sections comparing control (a) and collagen coated (b) implant interfaces. Note the very low density typical of trabecular bone and the definitely more vigorous 
bone regeneration at the collagen coated Ti surface. The large interconnected pores between the struts and sheets of trabecular bone tissue are filled by marrow that provides mesenchymal cells for bone regeneration. Cellular differentiation is induced by biochemical cues, both soluble and insoluble, in the environment immediately surrounding cells. Insoluble cues arise largely from cellular binding to ECM proteins, chief among them collagen (Salasznyk et al., 2004). Is the implant interface of Fig. 5 b providing the insoluble cues required for the differentiation of mesenchymal cells along the osteogenic pathway, mimicking in part the function of actual ECM? This is the spirit of BMTiS, more studies are required to confirm promising indications supplied by histology data.

A couple of other relevant papers have already been quoted in the RGDs section: Schliephake et al. (2005) compared $\mathrm{Ti}$, collagen I coated $\mathrm{Ti}$ and the latter with further immobilization of RGD at two different concentrations in foxhound implants in mandible (the coating procedures have already been described). Even if the focus of the study was RGD, data clearly show the role of collagen alone: after 1 month, volume density of the newly formed periimplant bone was significantly higher in all implants with organic coating, that is collagen and collagen plus RGD, without difference between collagen coating and RGD coatings. Bone implant contact was not different between the different organic coatings. After 3 months, both BIC and BVD were significantly higher in all implants with organic coating, than in implants with Ti surfaces. Thus, no direct evidence exists that the further RGD linking to collagen (that is obviously the best provider of RGD and more) bears further improvement; but evidence exists that collagen improves BIC and BVD as compared to $\mathrm{Ti}$, in the spirit of this section.

The second, already quoted, paper is the recent work by Bernhardt et al (2005): the improvement of performances offered by collagen type I and III over RGD have been commented upon already (even if, as discussed in the conclusions section, the lack of surface characterization of RGD coated implants does not allow us to make definite statements on "what-kind-of-RGDcoated-implant" has actually been tested). However, a fascinating finding presented in this paper, that deserves further comment, is the different behaviour of collagen I Vs. collagen III - the latter seemingly inducing faster bone apposition in the less dense spongious bone. The paper suggests that this difference can be accounted for by the fact that collagen I has been described as critical in the signalling cascade for the expression of the mature osteoblast phenotype and mineralization of the ECM, proving particularly useful in settings with high tissue and cell density. Collagen type III, on the other hand, is associated with early phase phenomena, such as cell proliferation and matrix deposition and this could be of help in situation of low bone and cell density. If confirmed, these observations could open the way to finely-tuned BMTiS, where, depending on the specific site and application, a specific molecule or set of molecules could be used to its best effect.

Rammelt et al. (2004) presented a study in rat, involving coating by adsorption of type-I collagen on titanium rods. Coated and uncoated pins were inserted into the tibia of adult rats and histology and immunohistochemistry were performed at 1, 2, 4, 7, 14 and 28 days. Results show that, at day 4 , the interface around the collagen-coated implants displayed a granulation tissue with higher numbers of cathepsin D-positive mononucleated cells, compared to the uncoated implants. Active osteoblasts were increased around the collagen-coated pins at day 4 and 7. After 28 days of implantation, direct bone contact and newly formed bone averaged better around the collagen-coated pins as compared to uncoated pins, but the difference was not significant. Overall, these results suggest an increased early bone remodelling around titanium pins through collagen coating.

Contrary to previous findings, Svehla et al. (2005) observed no effect of fibrillar atelopeptide and PEG crosslinked collagens coatings, placed directly into porous sintered bead structures, on bone ingrowth - using a skeletally mature bicortical, bilateral ovine tibia model. Implants were either injected with $60 \mathrm{mg} / \mathrm{mL}$ bovine skin fibrillar collagen, $60 \mathrm{mg} / \mathrm{mL}$ bovine skin fibrillar collagen crosslinked with $0.5 \%$ disuccinimidylglutarate polyethelene glycol, or left without collagen. Bone ingrowth into the implants increased with time, although differences were not significant. At 4 weeks woven bone, that remodelled with time, was present within the pores. Both fibrillar and crosslinked forms of dermal type I collagen did not alter bone ingrowth significantly. The paper does not report detailed surface analysis and it is a bit difficult to compare the approach used in this paper with other approaches to collagen coating.

Beside collagen, a recent paper describes the use of bone sialoprotein coatings (O'Toole et al., 2004): BSP coated implants were implanted into rat femora, and evaluated at days 10, 20 and 30. Harvested femoral implants were subjected to pullout testing and then examined histologically. Results show osteoinductive activity of BSP-coated implants; pullout however was not affected by BSP coating.

\section{Conclusions}

In the sections above, existing works on BMTiS by peptides and ECM proteins were reviewed. Even considering the large differences between experimental approaches, level of sophistication of chemico-physical and biological evaluations, accuracy of experiments and statistical evaluation, it is reasonable to conclude that the soundness of the underlying principles is supported by experimental results; and that in vivo results exist that show that bone regeneration at the interface with titanium implant devices can be improved over that of plain Ti by surface modification by peptides or ECM proteins. The field defined by the opening quotations by Puleo and Nanci (1999) and Hammerle (2005) is an open and interesting reality, at least as far as animal studies are involved.

Crucial questions still remain, first of all the actual clinical benefits of the reported improvements. These data, however, depend on the specific application, and can only be addressed by specific clinical studies. Sterilization is 
an important issue for actual application of the surface concepts to implant devices. Several of the quoted papers meritoriously report the way samples were sterilized, partially relieving concerns related to stability to sterilization of the delicate molecular structures involved. Yet, sterilization, especially in the case of irradiation (gamma or beta rays) remains one of the main variables to be checked, because of concerns related to irradiationinduced cross-linking, ablation, oxidation or - in general, modification of the specific chemical structure. Shelf-life, or the expected lifetime of the molecularly engineered surface structure, packaged and sterilized, is another keypoint that deserves much attention, and that is not often tackled in the relevant literature.

Concerning peptide-based approaches, it is a matter of reflection that, despite much basic work aimed at finding sequences specifically targeted to bone cells and overcome the "universality" and lack of selectivity of the RGD signal, the most widely tested peptide in vivo just bears the RGD sequence.

Possibly for the reason mentioned above, and considering in vivo studies, it is of interest to observe that whenever the peptide approach is compared to the "whole protein" approach, the latter gives better or equivalent results. This point has been somehow discussed in the previous sections.

Another very important observation is the sensitivity of the bone tissue response to the details of surface chemistry, to the point that even differences between collagen I and collagen III coatings were captured in one paper (Bernhardt et al., 2005). This is very different from the generalized lack of sensitivity to surface chemistry widely described by Ratner in soft tissue implants (Ratner, 1993; Ratner and Bryant, 2004). In fact, the same collagen coating that improves cortical and trabecular bone response in rabbit, yields the same unspecific encapsulation provided by untreated Ti when tested in rabbit muscle (Morra et al., 2003). Obviously, primary stability in the bone bed is a mandatory requirement to elicit surface-chemistry dependent bone regeneration, stressing the role of micromotion and modulus mismatch in the ubiquitous foreign body response detected in soft tissue implants.

The very same sensitivity to the details of surface chemistry makes it mandatory to provide, together with biological data, thorough surface chemical characterization. Many of the quoted papers provide very nice investigations by a range of surface sensitive techniques. But sometimes, especially when it comes to papers presenting in vivo data, often stemming from medical environments, surface characterization is completely lacking, and this occurrence seriously reduces the information content and the usefulness of the data. Actual surface chemistry data are required to be in the position to speculate on the actual role of surface chemistry on the experimental outcome.

Finally, interpretation of both reviewed approaches is based solely on effects on cell adhesion and/or differentiation. That is, they are viewed on the light of the cell-adhesion and growth paradigm (Larsson et al., 2001). Present research on biomaterial science underlines the role of early phases and places the general device-tissue interaction in the broader frame of wound healing. Actually, bone cells reach the implant surface well after inflammatory cells and after several steps of the inflammation and wound-healing cascade (Larsson et al., 2001). Thus, even if data are interpreted in terms of bone cells-Ti surface interaction, the contribution of other mechanisms should not be excluded. Notoriously, for instance, collagen exerts pro-coagulant activity that could also play a significant role, through enhanced platelet activation and concurring release of growth factors; and, as a consequence, in providing the temporary fibrin network matrix required for cell migration to the implant surface, as nicely described by Davies (2003). In the same vein, BMTiS strategies could not be necessarily limited at targeting the cell adhesion/differentiation couple. Targeting specific steps of the wound healing cascade and putting natural bone regeneration mechanisms in the optimum condition to perform could be an interesting strategy as well.

\section{References}

Auernheimer J, Zukowski D, Dahmen C, Kantlehner M, Enderle A, Goodman SL, Kessler H (2005) Titanium implant materials with improved biocompatibility through coating with phosphonate-anchored cyclic RGD peptides, Chembiochem 6: 2034-2040.

Auernheimer J, Kessler H (2006) Benzylprotected aromatic phosphonic acids for anchoring peptides on titanium. Bioorg Med Chem Lett 16: 271-273.

Barber TA, Golledge SL, Castner DG, Healy KE (2003) Peptide-modified p(AAm-co-EG/AAc) IPNs grafted to bulk titanium modulate osteoblast behavior in vitro. $\mathrm{J}$ Biomed Mater Res A 64: 38-47.

Bearinger JP, Castner DG, Healy KE (1998) Biomolecular modification of $\mathrm{p}$ (AAm-co-EG/AA) IPNs supports osteoblast adhesion and phenotypic expression. J Biomater Sci Polym Ed 9: 629-652.

Becker D, Geissler U, Hempel U, Bierbaum S, Scharnweber D, Worch H, Wenzel KW (2002) Proliferation and differentiation of rat calvarial osteoblasts on type I collagen-coated titanium alloy. J Biomed Mater Res 59: 516-527.

Bernhardt R, van den Dolder J, Bierbaum S, Beutner R, Scharnweber D, Jansen J, Beckmann F, Worch H (2005) Osteoconductive modifications of Ti-implants in a goat defect model: characterization of bone growth with SR $\mu \mathrm{CT}$ and histology, Biomaterials 26: 3009-3019.

Bierbaum S, Beutner R, Hanke T, Scharnweber D, Hempel U, Worch H (2003a) Modification of Ti6Al4V surfaces using collagen I, III, characteristics of the adsorbed matrix. J Biomed Mater Res A 67: 421-430.

Bierbaum S, Hempel U, Geissler U, Hanke T, Scharnweber D, Wenzel KW, Worch (2003b) Modification of Ti6AL4V surfaces using collagen I, III, and fibronectin. II. Influence on osteoblast responses. J Biomed Mater Res A 67: 431-438.

Brunette DM, Tengvall P, Textor M, Thomsen P, Eds (2001) Titanium in Medicine. 1019pp, Springer, Berlin. 
Cavalcant-Adam EA, Shapiro IM, Composto RJ, Macarak EJ, Adams CS (2002) RGD peptides immobilized on a mechanically deformable surface promote osteoblast differentiation. J Bone Miner Res 17: 2130-2140.

Cooper LF, Zhou Y, Takebe J, Guo J, Abron A, Holmen A, Ellingsen JE (2006) Fluoride modification effects on osteoblast behavior and bone formation at $\mathrm{TiO}_{2}$ grit-blasted c.p. titanium endosseous implants. Biomaterials 27: 926936.

Cunningham BW (2004) Basic scientific considerations in total disc arthroplasty. Spine J 4: 219S230S.

Davies JE, Ed (1991) The bone-biomaterial interface. $502 \mathrm{pp}$, University of Toronto Press, Toronto.

Davies JE, Ed (2000) Bone Engineering. 656pp, emsquared Inc., Toronto.

Davies JE (2003) Understanding peri-implant endosseous healing J Dent Ed 67:932-949

De Giglio E, Sabbatini L, Zambonin PG (1999) Development and analytical characterization of cysteinegrafted polypyrrole films electrosynthesized on Pt- and Ti-substrates as precursors of bioactive interfaces $\mathrm{J}$ Biomater Sci Polym Ed 10: 845-858.

De Giglio E, Sabbatini L, Colucci S, Zambonin G. (2000) Synthesis, analytical characterization, and osteoblast adhesion properties on RGD-grafted polypyrrole coatings on titanium substrates. J Biomater Sci Polym Ed 11: 1073-1083.

De Giglio E, De Gennaro L, Sabbatini L, Zambonin G. (2001) Analytical characterization of collagen- and/or hydroxyapatite-modified polypyrrole films electrosynthesized on Ti-substrates for the development of new bioactive surfaces. J Biomater Sci Polym Ed 12: 63-76.

Dean JW 3rd, Culbertson KC, D’Angelo AM (1995) Fibronectin and laminin enhance gingival cell attachment to dental implant surfaces in vitro. Int J Oral Maxillofac Implants 10: 721-728.

Dee KC, Rueger DC, Andersen TT, Bizios R. (1996) Conditions which promote mineralization at the boneimplant interface: a model in vitro study. Biomaterials 17: 209-215.

Dee KC, Andersen TT, Bizios R (1998) Design and function of novel osteoblast-adhesive peptides for chemical modification of biomaterials. J Biomed Mater Res 40: 371377.

Dettin M, Conconi MT, Gambaretto R, Pasquato A, Folin M, Di Bello C, Parnigotto PP (2002) Novel osteoblast-adhesive peptides for dental/orthopedic biomaterials. J Biomed Mater Res 60: 466-471.

El-Ghannam A, Starr L, Jones J (1998) Laminin-5 coating enhances epithelial cell attachment, spreading, and hemidesmosome assembly on Ti-6Al-4V implant materials in vitro. J Biomed Mater Res 41: 30-40.

Elmengaard B, Bechtold JE, Soballe K (2005a) In vivo effects of RGD-coated titanium implants inserted in two bone-gap models. J Biomed Mater Res A 75: 249-55.

Elmengaard B, Bechtold JE, Soballe K (2005b) In vivo study of the effect of RGD treatment on bone ongrowth on press-fit titanium alloy implants. Biomaterials 26: 35213526.
Endo K (1995a) Chemical modification of metallic implant surfaces with biofunctional proteins (Part 1). Molecular structure and biological activity of a modified NiTi alloy surface. Dent Mater J 14: 185-198.

Endo K (1995b) Chemical modification of metallic implant surfaces with biofunctional proteins (Part 2). Corrosion resistance of a chemically modified NiTi alloy. Dent Mater J 14: 199-210.

Ferris DM, Moodie GD, Dimond PM, Gioranni CW, Ehrlich MG, Valentini RF (1999) RGD-coated titanium implants stimulate increased bone formation in vivo. Biomaterials 20: 2323-2331.

Garcia AJ (2005) Get a grip: integrins in cellbiomaterial interactions. Biomaterials 26: 7525-7529.

Garcia AJ, Reyes CD (2005) Bio-adhesive surfaces to promote osteoblast differentiation and bone formation. $\mathrm{J}$ Dent Res 84: 407-413.

Geissler U, Hempel U, Wolf C, Scharnweber D, Worch H, Wenzel K (2000) Collagen type I-coating of Ti6Al4V promotes adhesion of osteoblasts. J Biomed Mater Res 51: $752-760$

Germanier Y, Tosatti S, Broggini N, Textor M, Buser D (submitted Dec 2004) Enhanced bone apposition around biofunctionalized sand-blasted and acid-etched titanium implant surfaces. A histomorphometric study in miniature pigs, submitted to Clin Oral Implants Res, available at: http://www.textorgroup.ch/pdf/publications/journals/126/ Germanier_et_al_submitted.pdf

Groll J, Fiedler J, Engelhard E, Ameringer T, Tugulu S, Klok HA, Brenner RE, Moeller M (2005) A novel star PEG-derived surface coating for specific cell adhesion. $\mathrm{J}$ Biomed Mater Res A 74: 607-617.

Grzesik WJ, Robey PG (1994) Bone matrix RGD glycoproteins: immunolocalization and interaction with human primary osteoblastic bone cells in vitro. J Bone Min Res 9: 487-493.

Hammerle C (2005) Current Issues Forum. Int J Oral Maxillofacial Implants 20: 311-312.

Hansson KM, Tosatti S, Isaksson J, Wettero J, Textor M, Lindahl TL, Tengvall P (2005) Whole blood coagulation on protein adsorption-resistant PEG and peptide functionalised PEG-coated titanium surfaces. Biomaterials 26: 861-872.

Houseman BT, Mrksich M (2001) The microenvironment of immobilized Arg-Gly-Asp peptides is an important determinant of cell adhesion. Biomaterials 22: 943-955.

Huang H, Zhao Y, Liu Z, Zhang Y, Zhang H, Fu T, Ma $X$ (2003) Enhanced osteoblast functions on RGD immobilized surface. J Oral Implantol 29: 73-79.

Jikko A, Harris SE, Chen D, Mendrick DL, Damsky $\mathrm{CH}$ (1999) Collagen integrin receptors regulate early osteoblast differentiation induced by BMP-2. J Bone Miner Res 14: 1075-1083.

Kantlehner M, Schaffner P, Finsinger D, Meyer J, Jonczyk A, Diefenbach B, Nies B, Holzemann G, Goodman SL, Kessler H (2000) Surface coating with cyclic RGD peptides stimulates osteoblast adhesion and proliferation as well as bone formation. Chembiochem 1: 107-114. 
Kim HW, Li LH, Lee EJ, Lee SH, Kim HE (2005) Fibrillar assembly and stability of collagen coating on titanium for improved osteoblast responses. J Biomed Mater Res A 75: 629-638.

Kroese-Deutman HC, Van Den Dolder J, Spauwen PHM, Jansen JA (2005) Influence of RGD-loaded titanium implants on bone formation in vivo. Tissue Eng 11: 1867 1875.

$\mathrm{Ku}$ Y, Chung CP, Jang JH (2005) The effect of the surface modification of titanium using a recombinant fragment of fibronectin and vitronectin on cell behaviour. Biomaterials 26: 5153-5157.

Larsson C, Esposito M, Liao H, Thomsen P (2001) The titanium-bone interface in vivo, in Brunette DM, Tengvall P, Textor M, Thomsen P, Eds (2001) In Titanium in Medicine, Springer, Berlin, 587-648.

Lebaron RG, Athanasiou KA (2000) Extracellular Matrix Cell Adhesion Peptides: Functional Applications in Orthopedic Materials. Tissue Eng 6: 85-104.

Lowenberg BF, Pilliar RM, Aubin JE, Sodek J, Melcher AH (1988) Cell attachment of human gingival fibroblasts in vitro to porous-surfaced titanium alloy discs coated with collagen and platelet-derived growth factor. Biomaterials 9: 302-309.

Massia SP, Hubbell JA (1990) Covalently attached GRGD on polymer surfaces promotes biospecific adhesion of mammalian cells. Ann N Y Acad Sci 589: 261-270.

Matsumura K, Hyon SH, Nakajima N, Peng C, Tsutsumi S (2000) Surface modification of poly(ethyleneco-vinyl alcohol) (EVA). Part I. Introduction of carboxyl groups and immobilization of collagen. J Biomed Mater Res 50: 512-517.

Matsumura K, Hyon SH, Nakajima N, Peng C, Iwata H, Tsutsumi S (2002) Adhesion between poly(ethyleneco-vinyl alcohol) (EVA) and titanium. J Biomed Mater Res 60: 309-315.

Mikulec LJ, Puleo DA (1996) Use of p-nitrophenyl chloroformate chemistry to immobilize protein on orthopedic biomaterials. J Biomed Mater Res 32: 203-208.

Miyamoto S, Katz BZ, Lafrenie RM, Yamada KM (1998) Fibronectin and integrins in cell adhesion, signaling, and morphogenesis. Ann NY Acad Sci 857: 119-128.

Mizuno M, Fujisawa R, Kuboki Y (2000) Type I collagen-induced osteoblastic differentiation of bonemarrow cells mediated by collagen- $\alpha 2 \beta 1$ integrin interaction. J Cell Physiol 184: 207-213.

Morra M, Cassinelli C, Cascardo G, Cahalan P, Cahalan L, Fini M, Giardino R (2003) Surface engineering of titanium by collagen immobilization. Surface characterization and in vitro and in vivo studies. Biomaterials 24: 4639-4654.

Morra M, Cassinelli C, Meda L, Fini M, Giavaresi G, Giardino R (2005a) Surface analysis and effects on interfacial bone microhardness of collagen-coated titanium implants: a rabbit model. Int J Oral Maxillofac Implants 20: 23-30.

Morra M, Cassinelli C, Fini M, Giardino R (2005b) Enhanced osteointegration by biochemical surface modification: covalent linking of collagen I to intervertebral metal disk surface. Eur Cell Mater 10 suppl 3: 6 .
Morra M, Cassinelli C, Cascardo G, Mazzucco L, Borzini P, Fini M, Giavaresi G, Giardino R (2006) Collagen I-coated porous titanium surfaces: mesenchymal cell adhesion and in vivo evaluation in trabecular bone implants. J Biomed Mater Res A - Published Online: 23 May 2006 DOI: 10.1002/jbm.a.30783.

Muller R, Abke J, Schnell E, Scharnweber D, Kujat R, Englert C, Taheri D, Nerlich M, Angele PNagai M, Hayakawa T, Fukatsu A, Yamamoto M, Fukumoto M, Nagahama F (2006) Influence of surface pretreatment of titanium- and cobalt-based biomaterials on covalent immobilization of fibrillar collagen. Biomaterials 27:40594068 .

Nagai M, Hayakawa T, Fukatsu A, Yamamoto M, Fukumoto M, Nagahama F, Mishima H, Yoshinari M, Nemoto K, Kato T (2002) In vitro study of collagen coating of titanium implants for initial cell attachment. Dent Mater J 21: 250-260.

Nanci A, West JD, Peru L, Brunet P, Sharma V, Zalzal S, McKee MD (1998) Chemical modification of titanium surfaces for covalent attachment of biological molecules. J Biomed Mater Res 40: 324-335.

O'Toole GC, Salih E, Gallagher C, FitzPatrick D, O'Higgins N, O'Rourke SK (2004) Bone sialoproteincoated femoral implants are osteoinductive but mechanically compromised. J Orthop Res 22: 641-646.

Pallu S, Bourget C, Bareille R, Labrugere C, Dard M, Sewing A, Jonczyk A, Vernizeau M, Christine Durrieu M, Amedee-Vilamitjana J (2005) The effect of cyclo-DfKRG peptide immobilization on titanium on the adhesion and differentiation of human osteoprogenitor cells. Biomaterials 26: 6932-6940.

Peng C, Tsutsumi S, Matsumura K, Nakajima N, Hyon SH (2001) Morphologic study and syntheses of type I collagen and fibronectin of human periodontal ligament cells cultured on poly(ethylene-co-vinyl alcohol) (EVA) with collagen immobilization. J Biomed Mater Res 54: 241-246.

Pham MT, Reuther H, Maitz MF (2003) Native extracellular matrix coating on Ti surfaces. J Biomed Mater Res 66A: 310-316.

Pierschbacher MD, Ruoslahti E (1984a) Cell attachment activity of fibronectin can be duplicated by small synthetic fragments of the molecule. Nature 309: 30-33.

Pierschbacher MD, Ruoslahti E (1984b) Variants of the cell recognition site of fibronectin that retain attachment-promoting activity. Proc Natl Acad Sci USA 81: 5985-5988.

Porte-Durrieu MC, Guillemot F, Pallu S, Labrugere C, Brouillaud B, Bareille R, Amedee J, Barthe N, Dard M, Baquey C (2004) Cyclo-(DfKRG) peptide grafting onto Ti-6Al-4V: physical characterization and interest towards human osteoprogenitor cells adhesion. Biomaterials 25: 4837-4846.

Puleo DA, Nanci A (1999) Understanding and controlling the bone-implant interface. Biomaterials 20:2311-2321.

Puleo DA, Kissling RA, Sheu MS (2002) A technique to immobilize bioactive proteins, including bone 
morphogenetic protein-4 (BMP-4), on titanium alloy. Biomaterials 23: 2079-2087.

Rammelt S, Schulze E, Wolf E, Scharnweber D, Holch M, Worch H Zwipp H (2002) Immunoistochemical charcaterization of the bone implant interface of collagen coatd titanium pins in the undecalcified rat-tibia. Eur J Trauma 28: 125-126.

Rammelt S, Schulze E, Bernhardt R, Hanisch U, Scharnweber D, Worch H, Zwipp H, Biewener A (2004) Coating of titanium implants with type-I collagen. J Orthop Res 22: 1025-1034.

Rammelt S, Illert T, Schneiders W, Scharnweber D, Worch H, Zwipp H (2005) Coating of titanium implants with collagen, RGD peptides and chondroitin sulphate. ICBME proceedings 12: 2B-02.

Ratner BD (1993) New ideas in biomaterials science: a path to engineered biomaterials. J Biomed Mater Res 27: $837-850$

Ratner BD, Bryant SJ (2004) Biomaterials: where we have been and where we are going. Ann Rev Biomed Eng 6: 41-75.

Reyes CD, Garcia AJ (2003) Engineering integrinspecific surfaces with a triple-helical collagen-mimetic peptide. J Biomed Mater Res A 65: 511-523.

Reyes CD, Garcia AJ (2004) $\alpha 2 \beta 1$ integrin-specific collagen-mimetic surfaces supporting osteoblastic differentiation. J Biomed Mater Res A 69: 591-600.

Rezania A, Healy KE (1999a) Integrin subunits responsible for adhesion of human osteoblast-like cells to biomimetic peptide surfaces. J Orthop Res 17: 615-623.

Rezania A, Healy KE (1999b) Biomimetic peptide surfaces that regulate adhesion, spreading, cytoskeletal organization, and mineralization of the matrix deposited by osteoblast-like cells. Biotechnol Prog 15: 19-32.

Rezania A, Healy KE (2000) The effect of peptide surface density on mineralization of a matrix deposited by osteogenic cells. J Biomed Mater Res 52: 595-600.

Roehlecke C, Witt M, Kasper M, Schulze E, Wolf C, Hofer A, Funk RW (2001) Synergistic effect of titanium alloy and collagen type I on cell adhesion, proliferation and differentiation of osteoblast-like cells, Cells Tissues Organs 168: 178-187.

Rupp F, Scheideler L, Olshanska N, de Wild M, Wieland M, Geis-Gerstorfer J (2006) Enhancing surface free energy and hydrophilicity through chemical modification of microstructured titanium implant surfaces. J Biomed Mater Res 76A: 323-334.

Salasznyk RM, Williams WA, Boskey A, Batorsky A, Plopper GE (2004) Adhesion to vitronectin and collagen I promotes osteogenic differentiation of human mesenchymal stem cells. J Biomed Biotechnol 1: 24-34.

Schliephake H, Scharnweber D, Dard M, Rossler S, Sewing A, Meyer J, Hoogestraat D (2002) Effect of RGD peptide coating of titanium implants on periimplant bone formation in the alveolar crest. An experimental pilot study in dogs. Clin Oral Implants Res 13: 312-319.
Schliephake H, Scharnweber D, Dard M, Sewing A, Aref A, Roessler S (2005) Functionalization of dental implant surfaces using adhesion molecules. J Biomed Mater Res Part B: Appl Biomater 73B: 88-96.

Schuler M, Owen GR, Hamilton DW, de Wild M, Textor M, Brunette DM, Tosatti SG (2006) Biomimetic modification of titanium dental implant model surfaces using the RGDSP-peptide sequence: a cell morphology study. Biomaterials 27: 4003-4015.

Senyah N, Hildebrand G, Liefeith K (2005) Comparison between RGD-peptide-modified titanium and borosilicate surfaces. Anal Bioanal Chem 383: 758-762.

Svehla M, Morberg P, Bruce W, Walsh WR (2005) No effect of a type I collagen gel coating in uncemented implant fixation. J Biomed Mater Res B Appl Biomater 74: 423-428.

Tamura RN, Oda D, Quaranta V, Plopper G, Lambert R, Glaser S, Jones JC (1997) Coating of titanium alloy with soluble laminin-5 promotes cell attachment and hemidesmosome assembly in gingival epithelial cells: potential application to dental implants. J Periodontal Res 32: $287-294$

Tosatti S, De Paul SM, Askendal A, VandeVondele S, Hubbell JA, Tengvall P, Textor M (2003) Peptide functionalized poly(L-lysine)-g-poly(ethylene glycol) on titanium: resistance to protein adsorption in full heparinized human blood plasma. Biomaterials 24: 4949-4958.

Tosatti S, Schwartz Z, Campbell C, Cochran DL, VandeVondele S, Hubbell JA, Denzer A, Simpson J, Wieland M, Lohmann CH, Textor M, Boyan BD (2004) RGD-containing peptide GCRGYGRGDSPG reduces enhancement of osteoblast differentiation by poly(Llysine)-graft-poly(ethylene glycol)-coated titanium surfaces. J Biomed Mater Res A 68: 458-472.

Van den Dolder J, Bancroft GN, Sikavitsas VI, Spauwen PH, Mikos AG, Jansen JA (2003) Effect of fibronectin- and collagen I-coated titanium fibre mesh on proliferation and differentiation of osteogenic cells. Tissue Eng 9: 505-515.

Van der Vondele S, Voros J, Hubbell JA (2003) RGDGrafted poly-1-lysine-graft-(polyethylene glycol) copolymers block non-specific protein adsorption while promoting cell adhesion. Biotechnology and Bioengineering 82: 784-790.

Xiao SJ, Textor M, Spencer ND, Wieland M, Keller B, Sigrist H (1997) Immobilization of the cell-adhesive peptide Arg-Gly-Asp-Cys (RGDC) on titanium surfaces by covalent chemical attachment. J Mater Sci Mater Med 8: $867-872$

Xiao S, Kenausis G, Textor M (2001) Biochemical modifcations of titanium surfaces. In: Titanium in Medicine, Brunette DM, Tengvall P, Textor M, Thomsen P, Eds., Springer, Berlin, 417-455.

Zreiqat H, Akin FA, Howlett CR, Markovic B, Haynes D, Lateef S, Hanley L (2003) Differentiation of human bone-derived cells grown on GRGDSP-peptide bound titanium surfaces. J Biomed Mater Res A 64: 105-113. 